\title{
The Roles of Dispersal, Fecundity, and Predation in the Population Persistence of an Oak (Quercus engelmannii) under Global Change
}

\author{
Erin Conlisk ${ }^{1 *}$, Dawn Lawson ${ }^{2}$, Alexandra D. Syphard ${ }^{3}$, Janet Franklin ${ }^{4}$, Lorraine Flint ${ }^{5}$, Alan Flint ${ }^{5}$, \\ Helen M. Regan'
}

1 Department of Biology, Center for Conservation Biology, University of California Riverside, Riverside, California, United States of America, 2 Environmental Sciences and Applied Systems Branch, Space and Naval Warfare Systems Center Pacific, San Diego, California, United States of America, 3 Conservation Biology Institute, La Mesa, California, United States of America, $\mathbf{4}$ School of Geographical Sciences and Urban Planning, Arizona State University, Tempe, Arizona, United States of America, $\mathbf{5}$ USGS California Water Science Center, Sacramento, California, United States of America

\begin{abstract}
A species' response to climate change depends on the interaction of biotic and abiotic factors that define future habitat suitability and species' ability to migrate or adapt. The interactive effects of processes such as fire, dispersal, and predation have not been thoroughly addressed in the climate change literature. Our objective was to examine how life history traits, short-term global change perturbations, and long-term climate change interact to affect the likely persistence of an oak species - Quercus engelmannii (Engelmann oak). Specifically, we combined dynamic species distribution models, which predict suitable habitat, with stochastic, stage-based metapopulation models, which project population trajectories, to evaluate the effects of three global change factors - climate change, land use change, and altered fire frequency emphasizing the roles of dispersal and seed predation. Our model predicted dramatic reduction in $Q$. engelmannii abundance, especially under drier climates and increased fire frequency. When masting lowers seed predation rates, decreased masting frequency leads to large abundance decreases. Current rates of dispersal are not likely to prevent these effects, although increased dispersal could mitigate population declines. The results suggest that habitat suitability predictions by themselves may under-estimate the impact of climate change for other species and locations.
\end{abstract}

Citation: Conlisk E, Lawson D, Syphard AD, Franklin J, Flint L, et al. (2012) The Roles of Dispersal, Fecundity, and Predation in the Population Persistence of an Oak (Quercus engelmannii) under Global Change. PLoS ONE 7(5): e36391. doi:10.1371/journal.pone.0036391

Editor: Gil Bohrer, Ohio State University, United States of America

Received January 13, 2012; Accepted April 6, 2012; Published May 18, 2012

Copyright: (c) 2012 Conlisk et al. This is an open-access article distributed under the terms of the Creative Commons Attribution License, which permits unrestricted use, distribution, and reproduction in any medium, provided the original author and source are credited.

Funding: Funding provided by National Science Foundation 488 (NSF-DEB-0824708) and the United States Department of Energy (DE-FC02-06ER64159) grants funded this project. The funders had no role in study design, data collection and analysis, decision to publish, or preparation of the manuscript.

Competing Interests: The authors have declared that no competing interests exist.

* E-mail: erin.conlisk@gmail.com

\section{Introduction}

Species distribution models (SDMs), which predict suitable habitat as a function of environmental conditions [1], have been widely used in conservation to estimate suitable habitat under climate change. Observations and predictions show climatically suitable habitat shifting in response to a warming climate, typically moving to higher elevations and latitudes [2], [3], [4]. Species' ability to avoid extinction depends in part on their ability to disperse from less to more suitable habitat [5]. Studies relying on SDMs and related methods have estimated how far certain species may need to migrate, but there is considerable uncertainty about whether plants can do so [6]. Comparisons of $\mathrm{C}^{14}$-dated pollen sequences against models of long-distance dispersal suggest that species may have been restricted historically by climate and not dispersal [7]. However, accelerated rates of current climate change may make migration impossible [8]. Combined with the uncertain impact of habitat fragmentation on dispersal and varying dispersal abilities, there is little consensus concerning the ability of species to keep pace with climate change.

Previous studies of the ability of species to keep up with climate change have typically focused on the distances between current and future suitable habitat [9]. Dispersal was presumed to occur if current and future suitable habitat predictions overlapped or the distances between them were small [5], [10]. Alternatively, the projected rate of change in time and space of topoclimatic environments can be estimated, thus describing the velocity that species within an ecosystem would have to travel to keep pace with climate change [11]. It was found that flat areas (low topographic relief) would require the largest velocities. Nevertheless, these various approaches did not directly address how species would accomplish the migration. Other studies have modeled life history traits and demographic dynamics explicitly through population spread models of wind-dispersed trees [12], [13]. Although these studies modeled realistic dispersal functions that include migration of individual propagules, they did not incorporate future habitat suitability. Our approach is to combine elements of both approaches to simultaneously model climate-induced change in metapopulations (spatially separated populations interacting through migration) and demographic processes of seed dispersal between these populations.

For plant species, fecundity and mode of dispersal underpin migration. Fecundity determines the number of available propagules while dispersal mode influences the distance and frequency 
of dispersal, namely the dispersal kernel. Both are expected to change with climate change, with potentially more complicated changes occurring in species, like oaks, that mast (i.e. exhibit regionally synchronized low seed production in most years and high seed production in occasional years). Acorn production has been shown to be temperature sensitive in Quercus crispula [14] and moisture sensitive in Q. ilex [15]. Maturation timing of acorns and adults may also change with climate change [16], with direct effects on survival and indirect effects on dispersal agents and seed predator avoidance [17]. Depending on how climate change impacts dispersal agents, masting events may cause decreased dispersal distances for some species ([18] for Quercus, [19] for tropical trees), but increased dispersal distances for others ([20] for pines). Decreased dispersal distance need not result in higher nearparent germination and establishment since higher overall seed survival and seedling density can preferentially occur at greater dispersal distances in Quercus masting years [18]. Uncertainty about the future relative proportions of different seed predators makes it difficult to predict the impact of climate change.

In addition to impacts on future habitat suitability, dispersal capacity, and seed predators, climate change may also affect species' persistence indirectly by altering ecosystem processes such as fire, which is especially important in Mediterranean ecosystems [21]. The mechanism for these potential effects would likely be climatic influences on fuel moisture, fuel load, and ignition probability [22]. Increases in fire frequency are also strongly associated with land use change and human population growth, particularly in rural areas [21], [23], [24]. Thus, we expect interactions among climate change, land use change, and altered fire regimes. For example, if habitat fragmentation decouples fires (effectively reducing fire size and thus the total area burned across habitat patches), then there may be an optimal degree of fragmentation for an obligate seeding population (plants requiring fire to germinate, but sensitive to frequent fires) [25]. Other studies found that altered fire frequency coupled with climate change could decrease obligate seeder populations [26], [27]. However, no previous studies have included detailed masting, dispersal, and seed predation dynamics in demographic predictions under global change. Further, few studies address the impact of altered fire frequency coupled with climate and land use change on fire resprouters (species with persistent individuals that resprout after a fire) despite numerous studies showing the minimal impact of high fire frequency on resprouters [24], [28]. Because altered fire regimes have the potential to dramatically alter species composition and ecosystem processes, understanding the relative role of fire in combination with other global change processes is essential to conservation management.

Here we study a resprouting oak species of conservation interest, Quercus engelmannii (Engelmann oak). It is a small (10-meter tall) white oak, endemic to the south coast montane section of the California floristic province. It is classified on the IUCN Red List as vulnerable, primarily due to habitat loss [29]. This emblematic oak is ecologically important, with acorns providing food resources for hundreds of species of insects and at least 100 species of birds and mammals. There is concern that $Q$. engelmannii are not regenerating adequately, possibly due to invasive plants, fire, and grazing of cattle [30], [31]. Insufficient oak recruitment is not

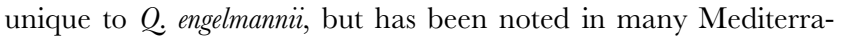
nean Quercus species [32]. Thus, forecasting potential impacts of climate change for slowly-regenerating Quercus species requires careful consideration of disturbance and life history traits, in addition to habitat suitability. Previous work on future oak habitat suitability has been criticized for neglecting life history [4], [33].
Land use change and altered disturbance regimes are considered to be primary threats to biodiversity in Mediterranean ecosystems [34], [35]. Because these threats, along with climate change, are expected to continue, we seek to understand the role of dispersal, fecundity (especially masting), and seed predation in population dynamics under the influence of climate change, land use change and altered fire frequency for a long-lived obligate resprouter, $Q$. engelmannii. By simultaneously modeling habitat suitability and demography, our approach allows us to answer critical questions that were not addressed by previous models, namely, how do life history traits, short-term global change perturbations (such as fire frequency and land use change), and long-term climate change interact to affect the likely persistence of oaks? Specifically, we ask: Which threats are the most serious for Q. engelmannii conservation? Do the threats reinforce each other? How important is dispersal to Q. engelmannii populations? Does (i) rare long distance dispersal or (ii) number of propagules have a greater influence on population persistence? How do masting and seed predation affect population persistence?

\section{Methods}

The overall modeling strategy is to use SDM predictions of habitat suitability over current and future climate to define the locations and carrying capacities of metapopulation patches, and to use a demographic model to determine the population dynamics within these patches. This approach to studying climate change, by linking dynamic bioclimatic envelopes with population models, is gaining traction within the conservation community [26], [27], [36].

Gurrent and future habitat distribution maps. Current distribution data (Fig. 1a) for Q. engelmannii was obtained from two sources: mapped habitat from the California Vegetation Mapping Program (CALVEG) [37] vegetation map (100-m resolution) and 139 presence locations from herbarium records and the 1930s Wieslander surveys [38]. Only three small patches $(<5$ ha) of Q. engelmannii remain in Los Angeles County (not shown in Fig. la).

We used Maxent presence-only species distribution modeling [39] to create suitability maps. Environmental predictors included climate (January minimum temperature, July maximum temperature, and annual precipitation), soil, and terrain variables important to predicting Southern California plant species distributions (see [40] and Appendix S1.2). Current climate grids were derived from 1971-2000 averaged Parameter-Elevation Regressions on Independent Slopes Model data (PRISM) [41] and spatially downscaled to a Digital Elevation Model [42]. The resolution of our climate, soil and terrain variables was $100 \mathrm{~m}$. The resulting Maxent habitat suitability predictions provided a

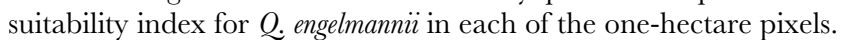
The training accuracy of the resulting current-climate suitability maps was AUC (area under the curve) $=0.88$. This suggests a reasonably accurate discrimination of occupied habitat [1]. The predicted distribution of currently suitable habitat was compared to maps of designated Q engelmannii habitat from CALVEG [37].

We used one land-use change scenario, one emission scenario (A2, which assumes business as usual $\mathrm{CO}_{2}$ emissions in a socioeconomically heterogeneous world), and two general circulation model projections (the Department of Energy and National Center for Atmospheric Research's Parallel Climate Model, or PCM, and the National Oceanic and Atmospheric Association's Geophysical Fluid Dynamic Laboratory's CM.2 model, or GFDL). PCM was generally less sensitive to climate forcings and predicted a slightly hotter and wetter climate, and the more sensitive GFDL predicted a substantially hotter and drier climate for California. These 

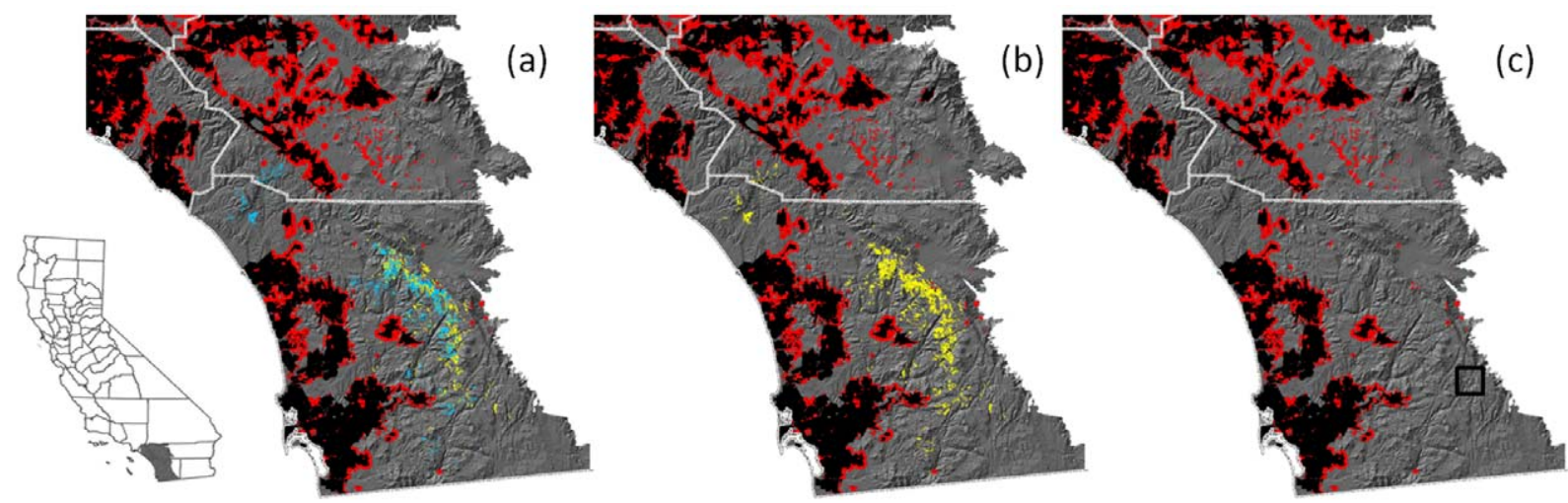

Figure 1. Map of the study area: most of San Diego and Orange Counties, western Riverside County, and the southern corners of Los Angeles and San Bernardino Counties (see inset). Map (a) shows habitat currently occupied by Q. engelmannii in cyan, and other habitat estimated to be currently suitable in yellow. Map (b) shows predicted 2100 suitable habitat in yellow for the PCM future climate scenario. Map (c) shows the same for the GFDL scenario (the box in the lower right surrounds the two small patches of remaining suitable habitat). In all three maps, the black represents current urban areas, and the red represents the extent of urban expansion by 2050. doi:10.1371/journal.pone.0036391.g001

climate models represent two very different precipitation scenarios and are the preferred models for California because their predictions of historic climate match observations [43]. Climate variables for 2070-2099 were averaged to represent predicted climate ca. 2099 for each climate scenario.

We created future habitat suitability maps for each climate projection by substituting future climate data in the suitability function obtained using the current climate. To create a time series of dynamic habitat maps across 100 years, we linearly interpolated habitat suitability in each cell over the model time horizon. This resulted in two sets (for PCM and GFDL projections) of 50 maps of suitable habitat for two year time-steps for 2000-2099.

To create dynamic projections of urban growth for 2000-2050, we developed spatially explicit, binary projections of urban development using the SLEUTH model [44]. When predicted urban development overlapped suitable habitat, these areas were considered unsuitable (see Fig. 1). Predictions of land use change beyond the next 50 years would be unduly speculative [45]. While urbanization has accelerated since 1920 [45], the rate of future urban growth is predicted to slow in the next 50 years due to lack of available land [44].

A patch-structured metapopulation map was constructed by selecting a threshold suitability value $(p=0.75)$ above which predicted suitability was retained and below which suitability was set to zero. The threshold was chosen such that the area predicted to be suitable was roughly equal to the area observed to be occupied [46]; thus, 15,000 ha of the CALVEG designated habitat was deemed suitable plus an additional 12,000 ha to account for potentially suitable areas that may be currently unoccupied. Habitat suitability maps were imported into the spatially explicit population modeling platform RAMAS GIS ${ }^{\circledR} 5.0$ [47]. Suitable patches were defined as clusters of 15 or more adjacent suitable one-hectare pixels. Smaller patches would have violated RAMAS limits on the total number of metapopulation patches; and sensitivity analyses exploring the deletion and addition of small patches showed that adding patches less than 15 hectares did not alter results. The carrying capacity of a patch was calculated as the sum of habitat suitabilities over all cells within the patch multiplied by a maximum density of 150 adult trees per hectare-equivalent [48]. The term "hectare-equivalent" reflects the fact that two patches with the same carrying capacity can have different areas due to differing habitat suitabilities within a patch.

Stage transitions in the demographic model. Five life stages were assumed: acorn, small seedling, large seedling, sapling, and adult tree. These stages were chosen to match available data from field experiments describing the average and standard deviation of transition rates of seedlings and saplings in the presence and absence of a fire over a two-year time step [49]. Data from the published literature were used to estimate values for all other parameters (see Appendix S1 for details). Time-steps were defined to be two years to match the observation interval of the field data (see Appendix S1.3). Vital rates depend on fire, time since last fire, masting, carrying capacity constraints, random disturbances and natural variability. In a baseline deterministic case when dispersal is absent and fire, masting, and capacity constraints do not apply, the life-stage populations in each patch would be governed by:

$$
\begin{aligned}
{\left[\begin{array}{c}
n_{1}(t+1) \\
n_{2}(t+1) \\
n_{3}(t+1) \\
n_{4}(t+1) \\
n_{5}(t+1)
\end{array}\right]=} & {\left[\begin{array}{ccccc}
0 & 0 & 0 & 2 & 20 \\
0.016 & 0.34 & 0.099 & 0 & 0 \\
0 & 0.27 & 0.47 & 0.037 & 0 \\
0 & 0.0061 & 0.17 & 0.88 & 10^{-6} \\
0 & 0 & 0 & 0.025 & 0.97
\end{array}\right] } \\
& \times\left[\begin{array}{l}
n_{1}(t) \\
n_{2}(t) \\
n_{3}(t) \\
n_{4}(t) \\
n_{5}(t)
\end{array}\right] .
\end{aligned}
$$

Here the $n_{i}(t)$ refer to the populations, by stage, ordered by increasing size, at time-step $t$. The numerical matrix shows the specified mean values of the vital rates. The first row of the matrix represents fecundities over a two-year time-step. The remaining entries represent (two-year) probabilities of survival (diagonals) and stage transitions (off-diagonals). For example, element $(2,3)$ in (1) describes the probability that a large seedling would be damaged and thus become a small seedling. Since $0.97^{100} \approx 0.05$, the adult 
survival probability of 0.97 corresponds to approximately a $5 \%$ chance of individuals living longer than 100 time-steps (200 years) [50].

The baseline case of eqn 1 is an expository starting point. The full model includes environmental and demographic stochasticity, disturbance and masting events, density dependence, response to fire, and patch dynamics. Different patches were interconnected by dispersal of acorns. New patches formed and old patches dissolved according to changes in suitable habitat. Realized vital rates in each time step and patch were randomly perturbed about their means to account for environmental stochasticity. During patch-specific episodes of fire, masting, and/or carrying capacity exceedance, the mean vital rates changed. Thus, the metapopulation consisted of many stage-based population vectors $n_{i}(t)$, one for each patch and time-step, changing according to multiple biological mechanisms, random disturbances, and stochasticity.

A first departure from the baseline case was the imposition of environmental and demographic stochasticity on the vital rates. For environmental stochasticity, each vital rate in each patch at each time-step was replaced by an independent draw from a lognormal distribution using the mean shown in eqn 1 and corresponding standard deviation [49] (see Appendix S1.3):

$$
\tilde{\sigma}=\left[\begin{array}{ccccc}
0 & 0 & 0 & 9.1 & 91 \\
0.014 & 0.020 & 0.14 & 0 & 0 \\
0 & 0.13 & 0.14 & 0.024 & 0 \\
0 & 0.018 & 0.088 & 0.050 & 0 \\
0 & 0 & 0 & 0.016 & 0.0010
\end{array}\right]
$$

The lognormal distribution allows for positive transition rates with fat tails towards higher survival probabilities. All survival probabilities were truncated at one. The vital rates thus drawn were used as patch-specific means to impose demographic stochasticity via independent draws from a Poisson distribution (for fecundities) or a multinomial distribution (for transition rates).

\section{Fecundity, Masting, and Acorn Predation}

Visual in-tree $Q$. engelmannii acorn counts from the California Acorn Survey Project (Koenig, personal communications) were translated into canopy level fecundity estimates using a regression for Q. douglasii in [51] (see Appendix S1.5). The effective number of viable acorns was the product of acorn production and survival rates from multiple seed predators. Seed predation was assumed to occur prior to dispersal and post-dispersal predation was implicit in germination rates. For predation of $Q$. ilex acorns by insects [52], and for predation of Q. rubra, Q. alba, and Q. palustris acorns by small vertebrates [18], the proportion of acorns killed varied according to the number of acorns produced, such that masting years had lower proportional acorn predation. We used data from these studies to determine predation rates, assuming that some of the acorns reported as "predated" were actually buried, thus facilitating germination. We converted fecundity estimates from one year time-steps to two year time-steps. Although these studies were performed on other Quercus species, the use of collateral data from similar species is a well-established practice when data for a target species are limited [53].

We developed six scenarios describing the number of viable acorns by combining three masting assumptions with two predation assumptions (see Table 1 and Appendix S1.5 for details). The three masting assumptions were no masting, masting with probability 0.121 in each time-step, and masting with probability 0.527 in each time-step. In the first predation assumption, predation was lower in masting time-steps (approximately $96 \%$ predation of acorns) than non-masting time-steps (approximately 99\% predation). In the second predation assumption, predation was approximately $96 \%$ in both masting and nonmasting time-steps. These masting frequencies were based on 16 years of Q. engelmannii acorn productivities (Koenig, personal communication), and on masting frequencies reported in [54]. Although we do not consider episodic bursts in germinability, our masting scenarios lead to episodic recruitment, which may occur in Quercus species [50].

\section{Fire}

For each patch and two-year time-step, the probability of fire was assumed to depend on time since last fire according to a discrete time Weibull hazard function:

$$
\lambda[T(t)]=\frac{c T(t)^{c-1}}{b^{c}} .
$$

Here $\lambda[T(t)]$ denotes the probability of a fire at time-step $t$ given that the last fire occurred $T(t)$ time-steps earlier; and $b$ and $c$ are scale and shape parameters [55]. We set $c=1.42$, suggesting a relatively low influence of time since last fire as is common in chaparral [55]. In simulations, we chose $b$ to represent average fire return intervals of 20,30, 40, 50, 60, 70, 80, and 120 years. There was also a no-fire scenario. Future fire frequency is highly uncertain because land use change will likely alter fire ignitions and climate change will likely alter fuel build up, fuel moisture, temperature, and precipitation. Thus, we explore a range of fire frequencies, noting that historic fire frequencies in San Diego County typically range from 10-90 years for a variety of vegetation types [56]. At the start of a simulation, each patch was given an initial value $T(0)$ drawn from the Weibull distribution. Fires were assumed to be spatially independent and to burn entire patches. The largest patch in our model was approximately 4,600 ha, much smaller than the six largest $(>100,000 \mathrm{ha})$ southern California fires that have occurred since 2001.

In a time-step when a fire occurs, the mean vital rates matrix changes to a fire matrix:

$$
\mathbf{F}=\left[\begin{array}{ccccc}
0 & 0 & 0 & 0 & 0 \\
0 & 0.41 & 0.13 & 0 & 0 \\
0 & 0.071 & 0.48 & 0.17 & 0 \\
0 & 0.0019 & 0.061 & 0.71 & 0.13 \\
0 & 0 & 0 & 0 & 0.86
\end{array}\right]
$$

Eqn 4 reflects research showing that adults resprout from canopy crowns, saplings resprout vigorously from basal root crowns, small seedlings rarely resprout, and large seedlings resprout more than small seedlings but less than saplings [30]. We assumed germination and fecundity to be zero in a fire time-step, with fecundity recovering completely to eqn 1 rates by the next timestep [57]. To reflect the lingering negative effects of fire on Quercus germination and seedling recruitment [48], for seven years following a fire we halved the germination rate relative to its eqn 1 value, akin to observed germination decreases due to canopy opening from coppicing [58]. Similarly, post-fire large seedling and sapling survival transition rates were increased by $10 \%$ to reflect the positive impact of canopy opening on these stages (see Appendix S1.7). 
Table 1. Six masting-predation scenarios.

\begin{tabular}{|c|c|c|c|c|c|}
\hline $\begin{array}{l}\text { Non-masting } \\
\text { predation rate }\end{array}$ & $\begin{array}{l}\text { Masting } \\
\text { predation rate }\end{array}$ & $\begin{array}{l}\text { Masting probability } \\
\text { per time-step }\end{array}$ & $\begin{array}{l}\text { Number of viable acorns per } \\
\text { non-masting time-step }\end{array}$ & $\begin{array}{l}\text { Number of viable acorns } \\
\text { per masting time-step }\end{array}$ & $\begin{array}{l}\text { Coefficient of variation in } \\
\text { acorns per time-step }\end{array}$ \\
\hline 0.992 & 0.965 & 0.527 & 20 & 162 & 0.95 \\
\hline 0.991 & 0.963 & 0.121 & 30 & 271 & 0.93 \\
\hline 0.991 & na & 0 & 36 & $\mathrm{Na}$ & 1.19 \\
\hline 0.965 & 0.965 & 0.527 & 82 & 187 & 1.00 \\
\hline 0.963 & 0.963 & 0.121 & 121 & 316 & 0.93 \\
\hline 0.967 & na & 0 & 127 & $\mathrm{Na}$ & 1.19 \\
\hline
\end{tabular}

The top three rows list the scenarios in which seed predation is lower in masting years. These first three rows are ordered by decreasing masting frequency. The bottom three rows list scenarios for which seed predation does not vary between masting and non-masting years. The last three rows are ordered by decreasing masting frequency. The coefficient of variation is the same in masting and non-masting years.

doi:10.1371/journal.pone.0036391.t001

\section{Dispersal}

Dispersal was assumed to depend on the distance between the centers of two patches. Although mice and squirrels disperse acorns over small within-patch distances, birds, in particular jays, were assumed to do the bulk of between-patch dispersal [59], [60]. Acorn woodpeckers live in territorial groups with arboreal hoards containing many acorns; thus they typically do not contribute to long-range dispersal [61]. The probability that a seed migrates from a patch $i$ to another patch $j$ was assumed to be:

$$
M_{i j}= \begin{cases}a \exp \left(-D_{i j} / d\right) & \text { when } D_{i j}<D_{\max } \\ 0 & \text { otherwise }\end{cases}
$$

where $D_{i j}$ is the distance between the patches; $D_{\max }$ is the maximum possible dispersal distance; and $a$ and $d$ are fixed parameters determining the maximum rate of dispersal and the rate of dispersal decline with distance. The coefficient $a$ might be interpreted as the distance-independent parameter of acorn flow. When the maximum dispersal distance is sufficiently large, $d$ can be interpreted (by reference to the mean of an exponential distribution) as the average dispersal distance. For any row $i$ of the symmetric matrix of $M_{i j}$ values, the row sum equals the expected total fraction of acorns leaving patch $i$ and, thus, may not exceed one. We use an exponential dispersal kernel because it fit empirical data of jay dispersal in oak woodlands with a high degree of statistical significance [59].

Because of the uncertainty in current and future dispersal distances, we explored a variety of dispersal parameters $\left(a, d, D_{\max }\right)$ guided by the few available empirical studies. The maximum dispersal distance observed in the literature was $4-\mathrm{km}$ for scrub jays (Cyanocitta cristata) in pin oak (Q. palustris) forests [62]. Studies observed average dispersal distances of $1.1 \mathrm{~km}$ for scrub jays in pin oak forests [63] and $0.263 \mathrm{~km}$ for European jays (Garrulous glandarius) in Holm oak (Q. ilex) forests [59]. Although genetic analyses of relatedness suggest limited long-range oak dispersal [64], results from preliminary simulations were pessimistic about the persistence of $Q$. engelmanii in the absence of long-range dispersal. Thus, we emphasized high dispersal distances to determine what might, in principle, mitigate population decline. Acorn "flow", or $a$, was varied from 0.0001 to 10 . Average dispersal distance, $d$, was varied from 0.3 to $10 \mathrm{~km}$ and maximum dispersal distance, $D_{\max }$, was varied from 4 to $40 \mathrm{~km}$.

\section{Carrying Capacity Constraints}

Each patch had its own carrying capacity, determined by habitat suitability and habitat area. When, as a result of fecundity or dispersal, a patch's abundance exceeded its capacity, survival rates (diagonal elements in the matrix of eqn 1) and stage-growth rates (subdiagonal elements in the matrix of eqn 1) were temporarily decreased to force a gradual decline in abundance, back to capacity (see Appendix S1.9). Individuals at the five life stages (acorns to adults) were assumed to contribute to patch abundance with stage-weights $(0,0.0025,0.025,0.25,1)$. The carrying capacity constraint required that abundance not exceed 150 adult-equivalent plants/hectare-equivalent. At the start of a simulation, habitable patches were assigned initial population densities of 90 adult-equivalents/ha, with a distribution by stage equal to an average distribution over trial runs.

\section{Model Scenarios}

We investigated a range of model scenarios, combining three possible climate projections (no change, PCM climate change projections, and GFDL climate change projections), two land use scenarios (no change or land use change), nine afire frequencies, 30 dispersal scenarios, and six coupled masting and seed predation scenarios. Each model was run 1000 times, with each run lasting 120 time steps. Stage and patch abundances were recorded at each time step. Expected minimum abundance (EMA), estimated as the average of the minimum abundances for the 1,000 model runs, was used to compare results across models. Expected minimum abundance effectively measures risk to population persistence because it is robust to parameter changes and captures the central tendency in the population's lower extreme [65]. There was little variation (less than $1 \%$ of reported values) among repeated 1000run simulations.

\section{Sensitivity Analyses}

Beyond our analyses of different dispersal distances, masting scenarios, and fire return intervals, we performed sensitivity analyses in vital rates by individually increasing each element by $10 \%$ over the mean reported in eqn 1 . For this analysis we considered two fire return intervals (fires every 20 years and no fires) and three dispersal scenarios (no dispersal, $d=1$ and $D_{\max }=4$, and $d=10$ and $D_{\max }=20$ ) for the PCM climate change scenario (Appendix S2.1). The vital rate with the greatest uncertainty was the germination parameter. Germination can vary from year to year due to a variety of environmental factors (discussed in Appendix S1.6). Thus, we did additional analyses increasing and decreasing that parameter by $50 \%$ and considering all fire return intervals (Appendix S2.2). Finally, we considered dispersal as a function of the carrying capacity of the receiving patch (Appendix S2.3). 


\section{Results}

Predicted suitable habitat for Q. engelmannii in 2100, under both the PCM and GFDL climate scenarios, was dramatically reduced in comparison to currently occupied habitat (Fig. 1). Climatically suitable habitat was predicted to shrink in extent and move southeastward to higher elevations in east San Diego County. Since these habitats are not likely to be diverted to urban development in the next 100 years, predicted land use change did not exert much influence on suitable habitat (Fig. 2). Nearly all suitable habitat remained after urban growth, whereas only $29.6 \%$ of suitable habitat remained under the PGM scenario, and almost no suitable habitat remained $(0.16 \%)$ under the GFDL scenario (Fig. 2a).

When population dynamics, in addition to habitat changes, were considered in the absence of fire, the general pattern remained the same. Under a no-dispersal scenario, the expected minimum abundance (EMA) under land use change was $99.7 \%$ of the EMA for no habitat change, while the EMA under the PCM and GFDL scenarios was $6.6 \%$ and $0 \%$ (respectively) of the EMA for no habitat change (Fig. 2b). EMAs improved slightly when dispersal was added, with EMAs unchanged under land-use change relative to no habitat change, and $10.7 \%$ and $0.02 \%$ (respectively) for the PCM and GFDL scenarios relative to no habitat change (Fig. 2c). Dispersal allowed Q. engelmannii to follow the migrating habitat, thus slightly mitigating projected climate change effects.

Under all average fire return intervals, EMA was very high for the constant habitat and land use change scenarios (Fig. 3a,b), but was dramatically reduced under the PCM and GFDL scenarios (Fig. 3c,d). Steep slopes of curves in Fig. 3 indicated the importance of fire across various habitat change and dispersal scenarios. EMA under all scenarios was lower for shorter average fire return intervals. The EMA under the PCM and GFDL climate change scenarios was more sensitive to fire return interval, especially with increasing dispersal (Fig. 3c,d). When there was essentially no change in the distribution of available habitat, the EMA was relatively insensitive to dispersal parameters (Fig. 3a,b).
This is not surprising given that land already occupied likely reflects Q. engelmannii's dispersal abilities. In contrast, when habitat area declined and shifted under either the PCM or the GFDL scenario, the EMA was sensitive to dispersal (Fig. 3c,d). Larger average dispersal distance $d$ and maximum dispersal distance $D_{\max }$ yielded greater EMAs, as intuition would suggest.

Figure 4 shows the effects of dispersal parameters on EMA, focusing solely on the PCM climate scenario. For given $d$ and $D_{\max }$ (average and maximum dispersal distance), and assuming no fires, the EMA increased with $a$, the distance-independent flow of acorns between patches (Fig. 4a). With $a$ held fixed at 0.01 , the EMA increased considerably as $d$ increased from 2 to $8 \mathrm{~km}$, regardless of $D_{\max }$ (Fig. 4b). The curves for $D_{\max }=20 \mathrm{~km}$ and $D_{\max }=40 \mathrm{~km}$ are nearly superimposed. (See also Appendix S3.)

Figure 5 shows the effects of the six masting-predation scenarios on EMA. Masting was important when predation rates change with acorn production (Figs. $5 \mathrm{a}-\mathrm{c}$ where the predation rate is $96 \%$ and $99 \%$ in masting and non-masting years, respectively). In these scenarios, higher masting frequency (masting probability of 0.527 in a time-step instead of 0.121 ) meant lower average predation rate and thus higher EMA. In contrast, when masting was not associated with lower predation (Figs. 5d-f), there was little advantage to sporadic bursts of high fecundity. The interaction between masting and predation was important.

These results were robust to sensitivity analyses (Appendix S2). Increasing each vital rate individually by $10 \%$ resulted in increased EMA of less than $10 \%$, with the exception of adult and sapling survival (or elements $(5,5)$ and $(4,4)$ in the matrix in eqn 1 ) where EMA increased by $9-37 \%$ and $10-22 \%$, respectively. Model rates were not especially sensitive to the most uncertain vital rate, or the germination parameter. Finally, the carrying capacity of the receiving patch had very little impact on the EMA under all dispersal scenarios. Regardless of the quantitative differences in EMA, the relative importance of climate change, fire frequency and dispersal were retained, suggesting that our model is robust to parameter uncertainties.

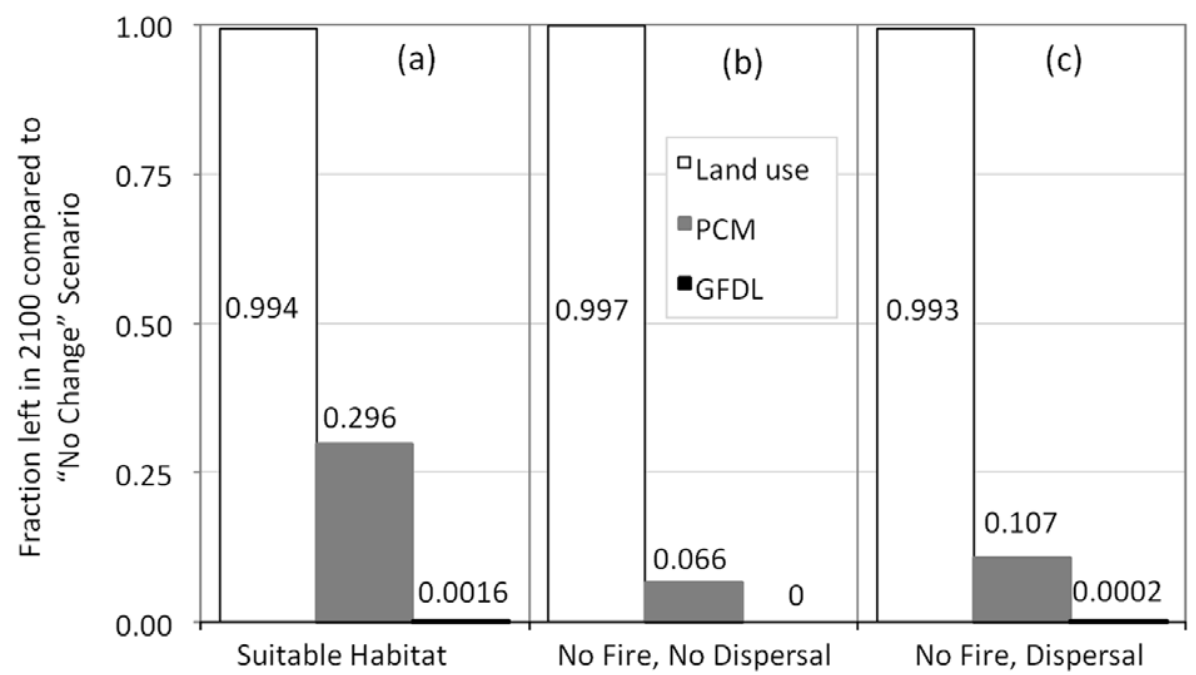

Figure 2. Q. engelmannii habitat ratios and population ratios under various assumptions. (a) Suitable habitat areas predicted for 2100 as ratios to suitable habitat areas estimated for 2000. The ratios are based only on habitat suitability maps. (b) The demographic component of the model is added, but with no fire and no dispersal. Each bar represents a ratio of a 2100 predicted population under a land use or climate change scenario to the 2100 predicted population under the no change scenario (where, in the no change scenario, suitable habitat is the same in 2000 and 2100). (c) Dispersal is added as described in text eqn 5, with the high values of average dispersal distance $d=10 \mathrm{~km}$, and maximum dispersal distance $D_{\max }=20 \mathrm{~km}$, and with the flow parameter $a=0.01$. All calculations for this figure assume the absence of fire. doi:10.1371/journal.pone.0036391.g002 
(a) No Habitat Change

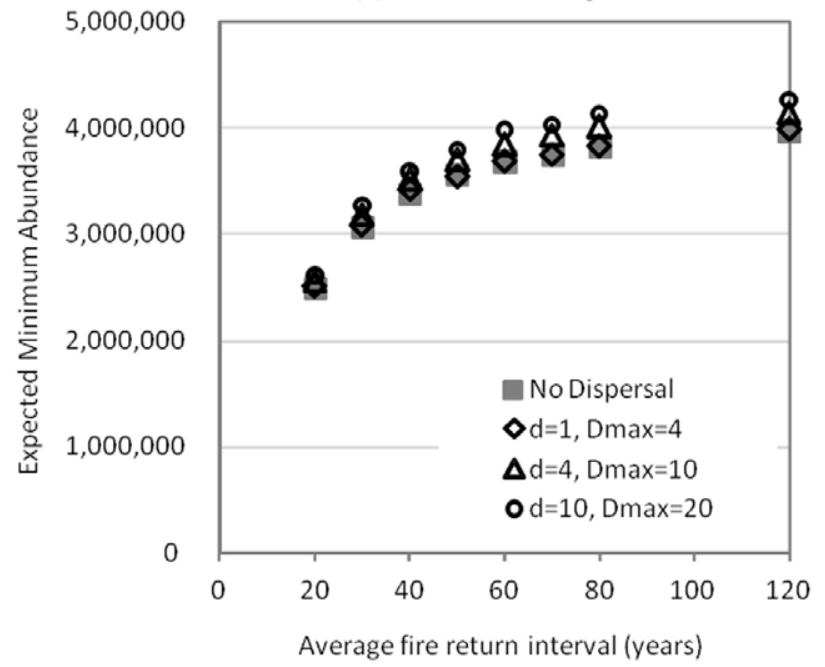

(c) PCM Climate Change

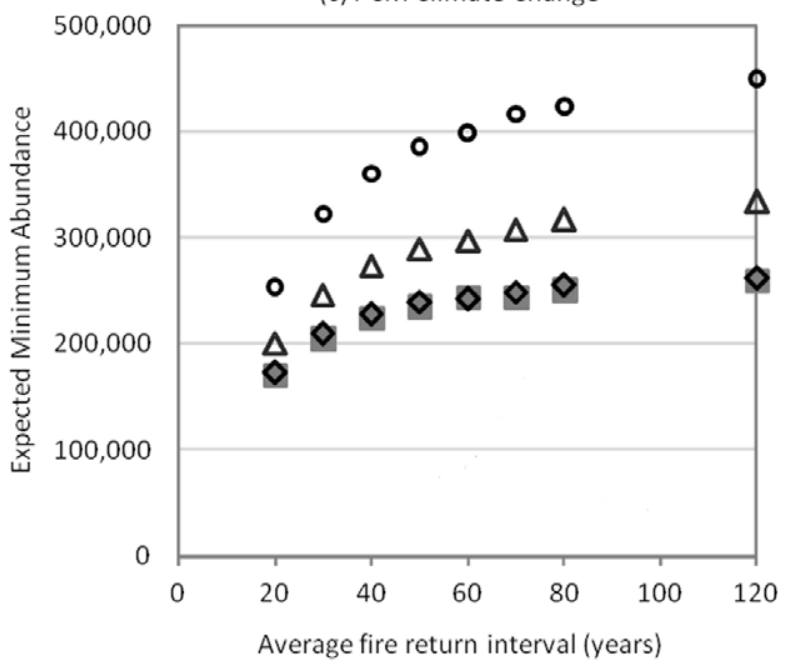

(b) Land Use Change

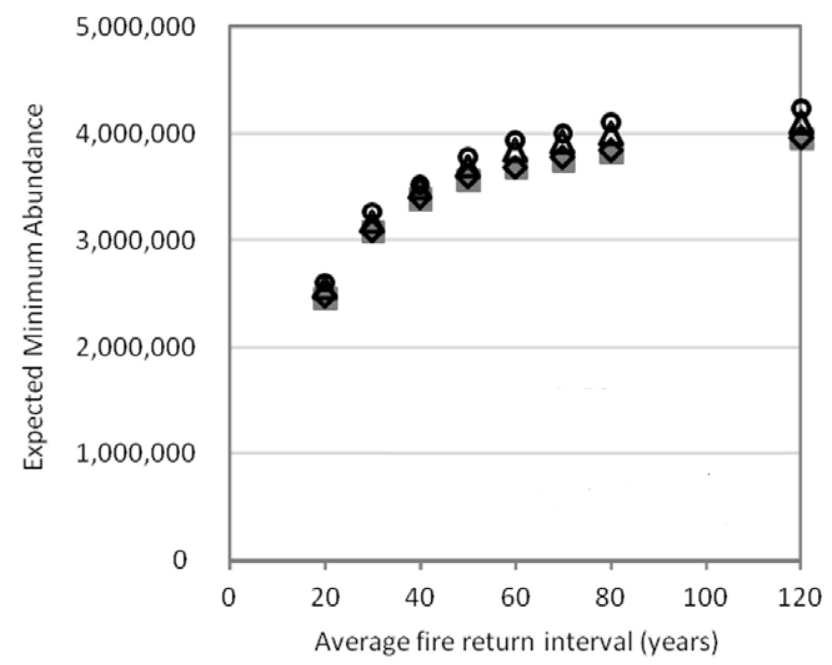

(d) GFDL Climate Change

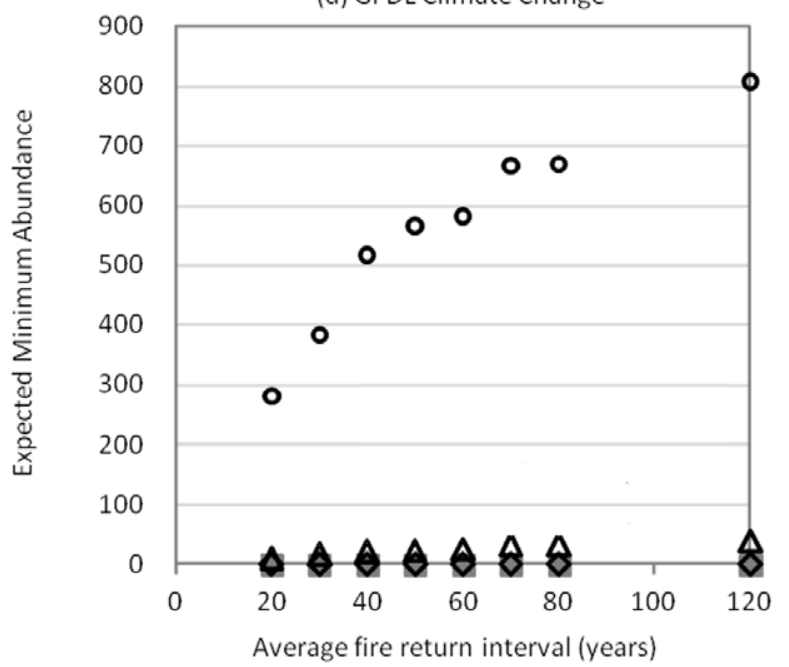

Figure 3. Expected minimum abundance for various dispersal, fire and habitat change scenarios. The four panels correspond to four climate and land use scenarios: (a) no habitat change, (b) land use change, (c) PCM climate change, and (d) GFDL climate change. Dispersal parameters are shown in (a) in $\mathrm{km}$. The settings for the average and maximum dispersal distances $d=1$ and $D_{\max }=4$ represent upper limits of empirically observed dispersal distances by jays. Throughout, the dispersal flow parameter is $a=0.01$. Note the change in vertical axis units across graphs. No error bars are included because they would be smaller than the symbols on the figure. The mean of 1,000 model runs varies by less than $1 \%$ between different 1,000-run simulations.

doi:10.1371/journal.pone.0036391.g003

\section{Discussion}

Maxent predicted that climatically-suitable habitat for the fire resprouter $Q$. engelmannii will decline dramatically under two future climate scenarios widely used for evaluating climate change in California. Under GFDL and PCM climate projections, assuming no migration, extinction and substantial population decline are predicted, respectively. The main difference between the two climate scenarios is the higher precipitation under PCM. The importance of water availability to $Q$. engelmannii has been demonstrated in greenhouse germination studies [31]. Field experiments show a positive correlation between Quercus acorn production and increased spring and summer rain [15].

Linking dynamic bioclimatic envelopes with a population model allowed us to project population size as a function of detailed, dynamic patch-to-patch dispersal. We chose the upper limit of empirically observed average and maximum dispersal distances by jays to be one and four kilometers, respectively (based on [62], [63]). There was almost no increase in EMA at these dispersal distances as compared to the no dispersal scenario. (Appendix S3 provides further details.) Altogether, our projections are pessimistic about $Q$. engelmannii persistence. Average dispersal distance and the flow of acorns were most important in mitigating population decline, suggesting that the establishment of "founder populations" depends critically on multiple propagules moving to new habitat. High acorn flow allows $Q$ engelmannii to take advantage of ephemeral habitat patches, where adequate abundances at the front of a shifting population are important for long-distance dispersal [66].

Another interpretation of our results is that a "fat-tailed" dispersal kernel would be needed to increase $Q$. engelmannii population persistence. We modeled dispersal assuming exponential decline in the fraction of acorns dispersing longer distances, 

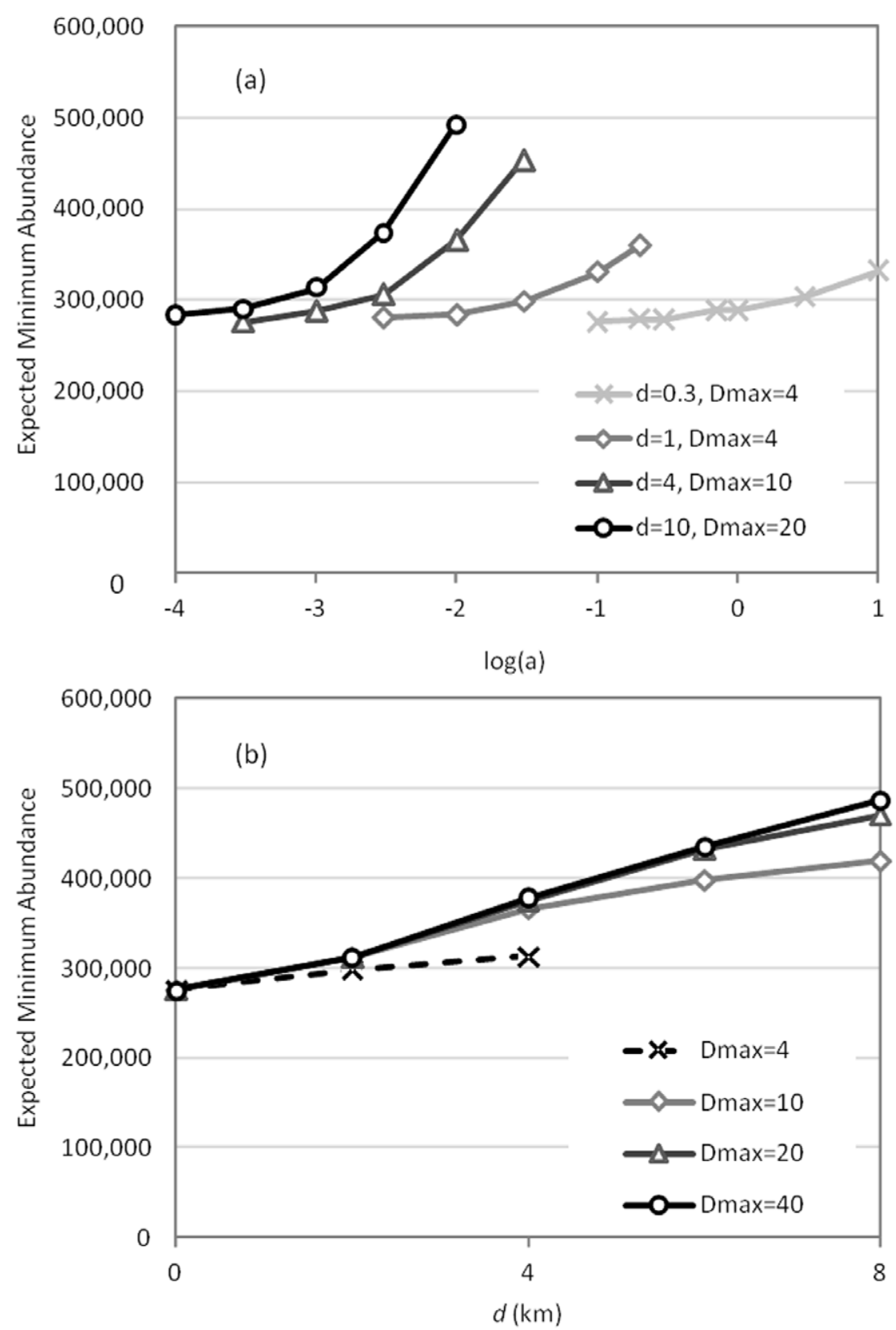

Figure 4. Expected minimum abundance graphed against the dispersal parameters $a$ (logged) and $d$ for a range of dispersal scenarios. Both panels assume the PCM scenario and the absence of fire. In (a), curves are truncated if total dispersal of acorns from a patch exceeds the number of acorns in that patch. In (b), the parameter $a$ is held fixed at 0.01 . The dashed line is truncated at $d=D_{\max }$. doi:10.1371/journal.pone.0036391.g004

based on [59]. However, that study also found that other functional forms fit the data with a high degree of statistical significance. In fact, the best fit was quadratic because there was a local peak for dispersal within a habitat patch and a long tail for dispersal between patches. Exploring additional dispersal functions and their influence on population persistence would be a fruitful future study.

Interaction between Q. engelmannii acorns and their predators have sizable estimated effects on population persistence. More frequent masting results in higher EMAs when relative predation rates (as a fraction of the acorn crop) are lower in masting years, but not when predation rates are the same. The first case is likely more realistic since differential acorn production in non-masting and masting years will likely keep predator populations low enough that acorn production in masting years will satiate predators' appetites. However, there is currently minimal data on the impact of climate change on masting, thus, model studies allow us to explore potential impacts.

Predation rates are based on data collected for other Quercus species due to a lack of predation studies performed on Q. engelmannii. Use of collateral data is frequently a necessity in population modeling [53]. Although the seed predators used to parameterize our models [18], [52], [67], [68]; see Appendix S1.5) are different than those present in $Q_{\text {. engelmannii habitat, we were }}$ careful to select predators that are functionally similar to $Q$. engelmannii predators. We did not identify seedling and sapling 


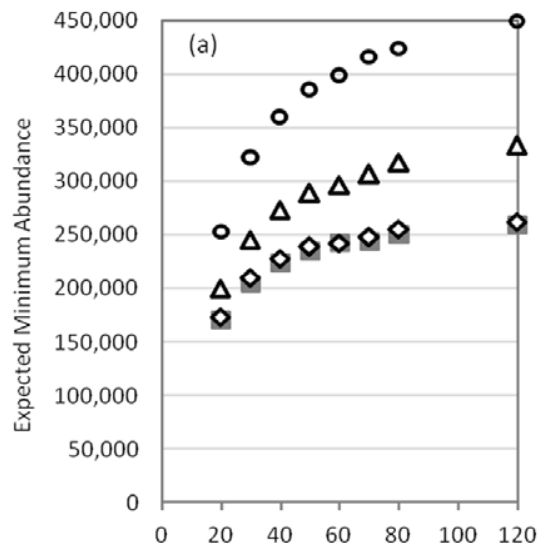

Average fire return interval (years)

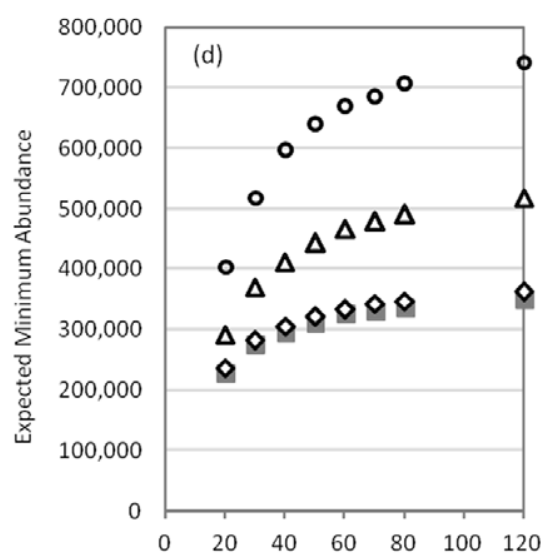

Average fire return interval (years)

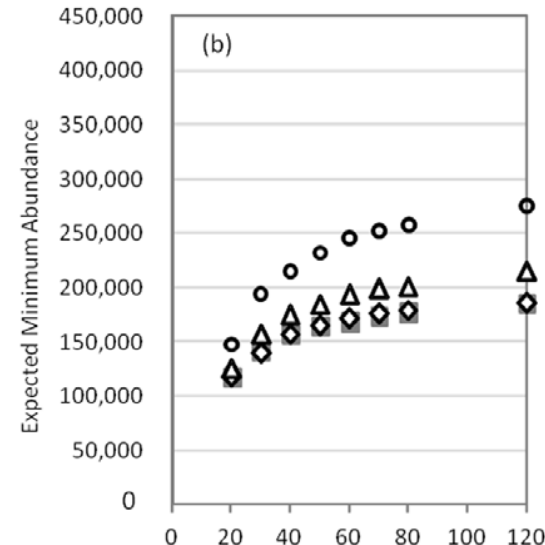

Average fire return interval (years)

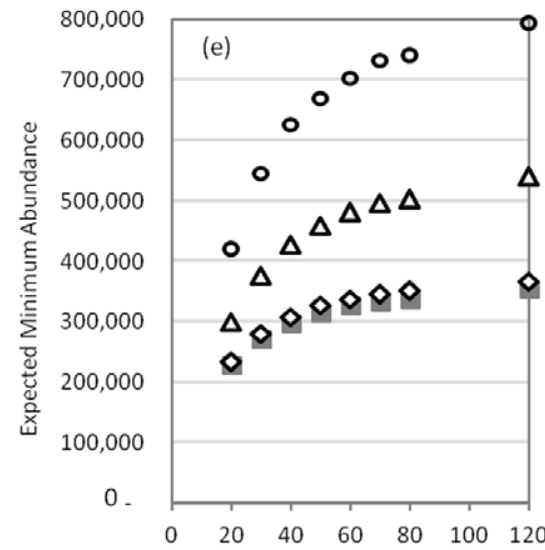

Average fire return interval (years)

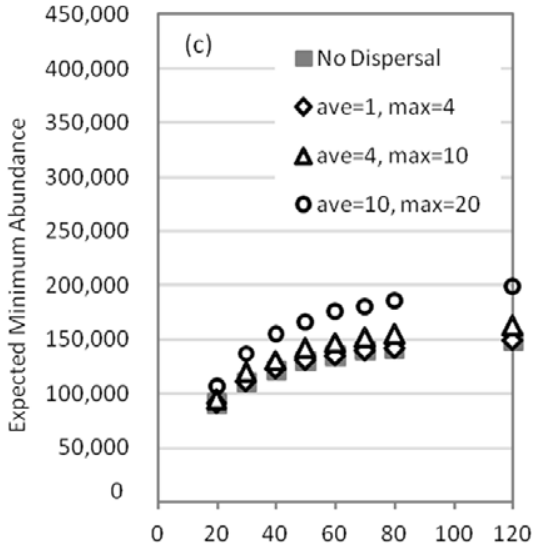

Average fire return interval (years)

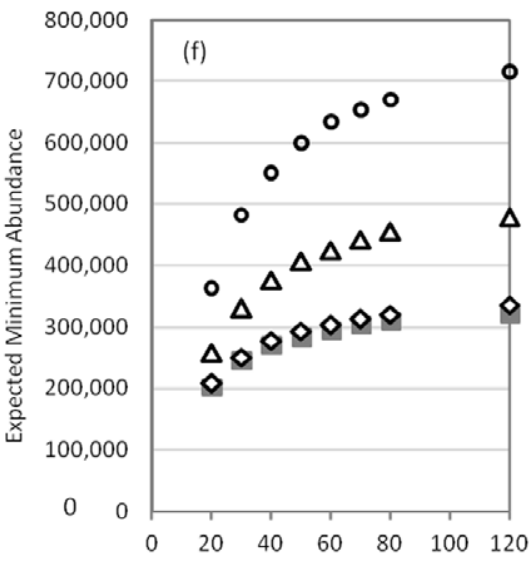

Average fire return interval (years)

Figure 5. Expected minimum abundance as a function of average fire return interval for six masting-predation scenarios. Masting treatments. (a) and (d): masting probability 0.53 in a time step (or, on average, roughly every three years). (b) and (e): masting probability 0.12 in a time step (or, on average, every 16 years). (c) and (f): no masting. Predation treatments. (a), (b), and (c): $\sim 96 \%$ predation in masting years and $\sim 99 \%$ predation in non-masting years. (d), (e), and (f): $\sim 96 \%$ predation in all time-steps. Within each of Figures (a)-(f), dispersal distances are varied as shown on the legend in (c).

doi:10.1371/journal.pone.0036391.g005

predation rates, despite their importance [32], because they were already incorporated in the vital rates reported in [49]. These approximations were appropriate for our objective of determining how changes in masting and predation might influence population persistence as compared to other threats.

Because Q. engelmannii's projected distribution of climaticallysuitable habitat is centered in eastern San Diego County, which is not expected to develop substantially, land use change will likely not have a substantial direct effect on $Q$. engelmannii populations. Nonetheless, there may be a substantial indirect effect of land use change through increasing fire frequency [23], [69]. Across all scenarios, the model projects EMA to be at least $50 \%$ higher for 120-year fire return intervals than for 20-year intervals, and at least 39\% higher for 60-year intervals than for 20-year intervals. Nevertheless, impacts from repeated fires are likely to be less detrimental to oak species than they are to obligate seeders [24], [70]. As a resprouter, Q. engelmannii can tolerate fire in many situations, though it is not suited to take advantage of fire.

Our modeling framework allows study of interactions among threats. For example, in the absence of dispersal, the EMA in landscapes with a fire return interval of 80 years is approximately $47 \%$ larger than the EMA in landscapes with a fire return interval of 20 years (under PGM climate change). With dispersal $(a, d$, $\left.D_{\max }\right)=(0.01,10,20)$, the corresponding increase is $67 \%$. Masting also interacts with fire, ameliorating the negative effect of frequent fire on EMA. Assuming no masting, the EMA in landscapes with a fire return interval of 80 years is approximately $54 \%$ larger than the EMA in landscapes with fire return interval of 20 years. With masting on average every three years, the $54 \%$ increase diminishes to $47 \%$ (under PCM climate change and no dispersal). Thus, conservation strategies aimed at reducing fire would help the population more in the event of decreased masting frequency.

Although our predictions suggest that climate change will be the biggest threat to $Q$ engelmannii, we believe that our models offer considerable insights compared to SDMs alone. The preceding paragraphs discuss how abundances change 39-67\% under different dispersal, fire, and masting scenarios. However, even in the absence of these different scenarios we see that projected population declines are proportionally greater than habitat losses (Fig. 2), a result we expect to be robust to different species and locations. We speculate that habitat suitability predictions underestimate the impact of climate change since they don't account for demographic factors. Some suggest that suitability 
predictions be interpreted as upper bound predictions of abundance (excepting population relicts or metapopulation sinks) [71]. However, some mechanistic models which consider growth and activity rates as a function of temperature predict greater tolerance to projected climate change, and therefore less habitat decline than typical SDMs [72]. If $Q$ e engelmannii tolerance, phenotypic plasticity, or adaptability to climate change is greater than we expect [73], our results may over-estimate Q. engelmannii population decline.

Since Q. engelmannii is a long-lived species with highly variable acorn production and germination, observations of these parameters over the duration of a typical empirical study (e.g. 10-20 years) lead to uncertainty in model parameterization. Thus, we performed sensitivity analyses on parameters in the vital rates matrix and found no change in the relative importance of climate change, dispersal, and fire frequency on population persistence (Appendix S2). Modeling long-lived species is also difficult because species may persist in a location long after the location has become unsuitable, creating an extinction debt. Because there is little data showing how survival and fecundity vary at the margins of Q. engelmannii's distribution, we cannot assess whether this model treats such an extinction debt conservatively. If we had data on how latitudinally or elevationally varying vital rates would affect population persistence, it would be interesting to build a model where climate change acts on vital rates through time as opposed to carrying capacity. In the meantime, decreased vigor at the margins of $Q$. engelmannii's distribution are represented by scaling the carrying capacity to SDM predicted suitability.

Our primary interest in this paper was to explore dispersal and altered species interactions (through seed predation) under climate change. To do so we created hundreds of models exploring these parameters. We did not explore sensitivity of results to additional model assumptions - additional climate models, emissions scenarios, SDMs, and SDM suitability thresholds for species presence. SDMs' high sensitivity to model inputs is well documented in the literature [74], [75]. Given the overwhelming difference between $Q$. engelmannii abundance under PCM and GFDL scenarios, it is clear that the choice of climate model, and possibly emissions scenario, greatly impacts population projections. However, the two models used in this study represent two opposing scenarios for Southern California and are likely to bracket much of the variability in the climate models. Although Maxent has been shown to be an accurate and robust model for

\section{References}

1. Franklin J (2009) Mapping Species Distributions: Spatial Inference and Prediction. Cambridge University Press, New York.

2. Chen I, Hill JK, Ohlemuller R, Roy DB, Thomas CD (2011) Rapid range shifts of species with high levels of climate warming. Science 222: 1024-1026.

3. Loarie SR, Carter BE, Hayhoe K, McMahon S, Moe R, et al. (2008) Climate change and the future of California's endemic flora. PLoS One 5: e2502.

4. Kueppers LM, Snyder MA, Sloan LC, Zavaleta ES, Fulfrost B (2005) Modeled regional climate change and California endemic oak ranges. Proceedings of the National Academy of Sciences USA 102: 16281-16286.

5. Midgley GF, Hughes GO, Thuiller W, Rebelo AG (2006) Migration rate limitations on climate change-induced range shifts in Cape Proteaceae. Diversity and Distribution 12: 555-562.

6. Svenning J, Skov F (2007) Could the tree diversity pattern in Europe be generated by postglacial dispersal limitation? Ecology Letters 10: 453-460.

7. Clark JS (1998) Why trees migrate so fast: confronting theory with dispersal biology and the paleorecord. American Naturalist 152: 204-224.

8. Malcolm J, Markham A, Neilson RP, Garaci M (2002) Estimated migration rates under scenarios of global climate change. Journal of Biogeography 29: 835-849.

9. Franklin J (2010) Moving beyond static species distribution models in support of conservation biogeography. Diversity and Distribution 16: 321-330.

10. Williams P, Hannah L, Adelman S, Midgley G, Araujo M, et al. (2005) Planning for climate change: identifying minimum-dispersal corridors for the Cape Proteaceae. Conservation Biology 19: 1063-1074. presence-only data [76], we speculate that the choice of Maxent has a big impact on model results given the uncertainty of SDM projection into novel environments [77], [78]. In the particular case of $Q$. engelmannii, we do not believe that small changes in the choice of SDM threshold would make a significant impact on population persistence. Continuous probability distributions for Q. engelmannii (Appendix S1.2) show clear boundaries between suitable and unsuitable habitat. However, if we did decrease the probability threshold, we would expect larger populations with the same ranking of population persistence under different global change scenarios.

Regardless of potential population sensitivity to different assumptions regarding climate model, emissions scenarios, SDM, and thresholds for species presence, we believe that our results are robust with regard to our research objectives. Realistic dispersal rates are not likely to mitigate population decline. However, increasing the number of propagules, and not the maximum distance of rare dispersal events, could theoretically increase abundance. Masting-dependent seed predation is predicted to have a big impact on $Q$. engelmannii populations in the event that masting becomes less frequent.

\section{Supporting Information}

Appendix S1 Detailed description of data and methods. (DOC)

Appendix S2 Sensitivity analysis. (DOC)

Appendix S3 Additional figures. (DOC)

\section{Acknowledgments}

We thank W. Koenig and J. Knops for California Acorn Survey Project data, M. Ikagami and F. Davis (University of California Santa Barbara) for climatic data, and M. Hawke (San Diego Natural History Museum) for Consortium of California Herbaria distribution data. Special thanks to R. Swab and J. Conlisk for insightful commentary.

\section{Author Contributions}

Conceived and designed the experiments: EC AS JF HR. Performed the experiments: EC. Analyzed the data: EC DL AS. Contributed reagents/ materials/analysis tools: DL AF LF. Wrote the paper: EG AS JF HR.

11. Loarie SR, Duffy PB, Hamilton H, Asner GP, Field CB, et al. (2009) The velocity of climate change. Nature 426: 1052-1055.

12. Nathan R, Horvitz N, He Y, Kuparinen A, Schurr FM, et al. (2011) Spread of North American wind-dispersed trees in future environments. Ecology Letters 14: 211-219.

13. Bullock JM, White SM, Prudhomme C, Tansey C, Perea R, et al. (2012) Modelling spread of British wind-dispersed plants under future wind speeds in a changing climate. Journal of Ecology 100: 104-115.

14. Nakamura M, Muller O, Tayanagi S, Nakaji T, Hiura T (2010) Experimental branch warming alters tall leaf phenology and acorn production. Agricultural Forest Meteorology 150: 1026-1029.

15. Perez-Ramos IM, Ourcival JM, Limousin JM, Rambal S (2010) Mast seeding under increasing drought: results from a long-term data set and from a rainfall exclusion experiment. Ecology 91: 3057-3068.

16. Germaine H, McPherson GR (1998) Effect of timing of precipitation and acorn harvest date on emergence of Quercus emoryi. Journal of Vegetation Science 9: 157-160.

17. Espelta JM, Bonal R, Sanchez-Humanes B (2009) Pre-dispersal acorn predation in mixed oak forests: interspecific differences are driven by the interplay among seed phenology, seed size and predator size. Journal of Ecology, 97: 1416-1423.

18. Moore JE, Swihart RK (2007) Importance of fragmentation-tolerant species as seed dispersers in disturbed landscapes. Oecologia 151: 663-674. 
19. Jansen PA, Bongers F, Hemerik L (2004) Seed mass and mast seeding enhance dispersal by a neotropical scatter-hoarding raodent. Ecological Monographs 74: 569-589.

20. Vander Wall SB (2002) Masting in animal-dispersed pines facilitates seed dispersal. Ecology 83: 3508-3516.

21. Syphard AD, Radeloff VC, Hawbaker TJ, Stewart SI (2009) Conservation threats due to human-caused increases in fire frequency in Mediterranean climate ecosystems. Conservation Biology 23: 758-769.

22. Bowman DM, Balch JK, Artaxo P, Bond WJ, Carlson JM, et al. (2009) Fire in the Earth System. Science 324: 481-484.

23. Syphard AD, Radeloff VC, Keeley JE, Hawbaker TJ, Clayton MK, et al. (2007) Human influence on California fire regimes. Ecological Applications 17: 1388-1402.

24. Syphard AD, Franklin J, Keeley JE (2006) Simulating the effects of frequent fire on southern California coastal shrublands. Ecological Applications 16: $1744-1756$.

25. Regan HM, Grookston JB, Swab R, Franklin J, Lawson DM (2010) Habitat fragmentation and altered fire regime create trade-off for an obligate seeding shrub. Ecology 91: 1114-1123.

26. Lawson DM, Regan HM, Zedler PH, Franklin J (2010) Cumulative effects of land use, altered fire regime and climate change on persistence of Ceanothus verrucosus, a rare, fire-dependent plant species. Global Change Biology 16: 2518-2529.

27. Keith DA, Akçakaya HR, Thuiller W, Midgley GF, Pearson RG, et al. (2008) Predicting extinction risks under climate change: coupling stochastic population models with dynamic bioclimatic habitat models. Biology Letters 4: 560-563.

28. Pausas JG, Bradstock RA, Keith DA, Keeley JE (2004) Plant functional traits in relation to fire in crown-fire ecosystems. Ecology 85: 1085-1100.

29. IUCN (2011) IUCN Red List of Threatened Species. Version 2011.1. <www. iucnredlist.org $>$. Downloaded on 20 October 2011.

30. Principe ZA (2002) Factors Affecting Engelmann Oak (Quercus engelmannii). Master's Thesis. San Diego State University.

31. Snow GE (1972) Some Factors Controlling the Establishment and Distribution of Quercus agrifolia and Quercus engelmannii Greene in Certain Southern California Oak Woodlands. PhD Thesis. Oregon State University.

32. Davis F, Tyler C, Mahill B (2011) Consumer control of oak demography in a Mediterranean-climate savanna. Ecosphere 2(10): 1-21.

33. Carmel Y, Flather CH (2006) Constrained range expansion and climate change assessment. Frontiers in Ecology 4: 178-179.

34. Millennium Ecosystem Assessment (2005) Ecosystems and human well-being: synthesis. Island Press, Washington, D. C p.

35. Chapin FS, Zavaleta ES, Eviner VT, Naylor RL, Vitousek PM, et al. (2000) Consequences of changing biodiversity. Nature 405: 234-242.

36. Anderson BJ, Akçakaya HR, Araujo MB, Fordham DA, Martinez-Meyer E, et al. (2009) Dynamics of range margins for metapopulations under climate change. Proeedings of the Royal Society London [Biology] 276: 1415-1420.

37. CALVEG [ESRI geodatabase of vegetation from 1997-2002 Landsat TM. CA Land Cover Mapping and Monitoring Program]. (2004) McClellan, C.A. USDA-Forest Service, Pacific Southwest Region, Remote Sensing Lab. Files: cveg.19s, cveg.30s, cveg.33s, cveg.37s, cveg.56s. [WWW document] Available: http: / / frap.fire.ca.gov/data/frapgisdata/download.asp? spatialdist $=2 \& \mathrm{rec}=\mathrm{c}-$ veg. Accessed 2010 July 1.

38. Kelly M, Allen-Diaz B, Kobzina N (2005) Digitization of a historic dataset: The Wieslander California vegetation type mapping project. Madroño 52: 191-201.

39. Phillips SJ, Anderson RP, Schapire RE (2006) Maximum entropy modelling of species geographic distributions. Ecological Modelling 190: 231-259.

40. Syphard AD, Franklin J (2009) Differences in spatial predictions among species distribution modeling methods vary with species traits and environmental predictors. Ecography 32: 907-918.

41. Daly C, Halbleib M, Smith JI, Gibson WP, Doggett MK, et al. (2008) Physiographically sensitive mapping of climatological temperature and precipitation across the conterminous United States. International Journal of Climatology 28: 2031-2064.

42. Flint LE, Flint AL (2012) Downscaling future climate scenarios to fine scales for hydrologic and ecological modeling and analysis. Ecological Processes 1: 1-15.

43. Cayan DR, Maurer EP, Dettinger MD, Tyree M, Hayhoe K (2008) Climate change scenarios for the California region. Climatic Change, 87: S21-S42.

44. Syphard AD, Clarke KC, Franklin J, Regan HM, McGinnis M (2011) Forecasts of habitat loss and fragmentation due to urban growth are sensitive to source of input data. Journal of Environmental Management 92: 1882-1893.

45. Candau JT (2002) Temporal calibration sensitivity of the SLEUTH urban growth model. Master's thesis. University of California, Santa Barbara.

46. Freeman EA, Moisen GG (2008) A comparison of the performance of threshold criteria for binary classification in terms of predicted prevalence. Ecological Modelling 217: 48-58.

47. Akçakaya HR, Root W (2005) RAMAS GIS 5: Linking Spatial Data with Population Viability Analysis. Applied Biomathematics, Setauket, New York.

48. Barbour MG, Billings WD (1989) North American Terrestrial Vegetation. Cambridge University Press, New York, NY.

49. Lawson D (1993) Effects of Fire on Stand Structure of Mixed Quercus agrifolia and Quercus engelmannii Woodlands. Master's Thesis. San Diego State University.
50. Plumb, TR, Pillsbury NH (1986) Proceedings of the Symposium on MultipleUse Management of California's Hardwood Resources. Forest Service, Pacific Southwest, General Technical Report PSW-100.

51. Koenig WD, Knops JMH, Carmen WJ, Stanback MT, Mumme RL (1994) Estimating acorn crops using visual surveys. Canadian Journal of Forest Research 24: 2105-2112.

52. Espelta JM, Cortez P, Molowny-Horas R, Sanchez-Humanes B, Retana J (2008) Masting mediated by summer drought reduces acorn predation in Mediterranean oak forests. Ecology 89: 805-817.

53. Linacre NA, Stewart-Oaten A, Burgman MA, Ades PK (2004) Incorporating collateral data in conservation biology. Conservation Biology 18(3): 768-774.

54. Sork VL (1993) Evolutionary ecology of mast-seeding in temperate and tropical oaks (Quercus spp.). Vegetatio 107/ 108: 133-147.

55. Polakow D, Bond W, Lindenberg N, Dunne T (1999) Ecosystem engineering as a consequence of natural selection: methods for testing Mutch's hypothesis from a comparative study of fire hazard rates. In Conference Proceedings: Bushfire 99-Australian Bushfire Conference. Charles Sturt University, Albury, Australia (eds. I. Lunt, D. Green and B. Lord).

56. Wells ML, O'Leary JF, Franklin J, Michaelsen J, McKinsey DE (2004) Variations in a regional fire regime related to vegetation type in San Diego County, California (USA). Landscape Ecol. 19: 138-152.

57. Abrahamson W, Layne J (2002) Post-fire recovery of acorn production by four oak species in southern ridge sandhill association in south-central Florida. American Journal of Botany 89: 119-123.

58. Espelta JM, Riba M, Retana J (1995) Patterns of seedling recruitment in WestMediterranean Quercus ilex forests influenced by canopy development. Journal of Vegetation Science 6: 465-472.

59. Gomez JM (2003) Spatial patterns in long-distance dispersal of Quercus ilex acorns by jays in a heterogeneous landscape. Ecography 26: 573-584.

60. den Ouden J, Jansen PA, Smit R (2004) Chapter 13: Jays, mice and oaks: predation and dispersal of Quercus robur and Q. petraea in North-western Europe. In Seed Fate: Predation, Dispersal and Seedling Establishment. Editors P.M. Forget, J.E. Lambert, and P.E. Hulme. CABI Publishing. Wallingford, Oxon.

61. Scofield DG, Sork VL, Smouse PE (2010) Influence of acorn woodpecker social behavior on transport of coast live oak (Quercus agrifolia) acorns in a southern California in a southern oak savanna. Journal of Ecology 98: 561-572.

62. Dixon MD, Johnson WC, Adkisson CS (1997) Effects of weevil larvae on acorn use by blue jays. Oecologia 111: 201-208.

63. Darley-Hill S, Johnson WC (1981) Acorn dispersal by the blue jay (Cyanocitta cristata). Oecologia 50: 231-232.

64. Grivet D, Smouse PE, Sork VL (2005) A novel approach to an old problem: tracking dispersed seeds. Molecular Ecology, 14: 3585-3595.

65. McCarthy MA, Thompson C (2006) Expected minimum population size as a measure of threat. Animal Conservation 4(4): 351-355.

66. Iverson LR, Schwartz MW, Prasad A (2004) How fast and how far might tree species migrate in the eastern United States due to climate change? Global Ecology and Biogeography 13: 209-219.

67. Gomez JM (2004) Importance of microhabitat and acorn burial on Ouercus ilex early recruitment: non-additive effects on multiple demographic processes. Plant Ecology 172: 287-297

68. Borchert MI, Davis FW, Michaelsen J, Oyler LD (1989) Interactions of factors affecting seedling recruitment of Blue Oak (Quercus douglasii) in California. Ecology, 70, 389-404.

69. Pincetl S, Rundel PW, DeBlasio JC, Silver D, Scott T, et al. (2008) It's the land use not the fuels: Fires and land development in southern California. Real Estate Review 37: 25-42.

70. Haidinger TL, Keeley JE (1993) Role of high fire frequency in destruction of mixed chaparral. Madroño 40: 141-147.

71. VanDerWal J, Shoo LP, Johnson GN, Williams SE (2009) Abundance and the environmental niche: Environmental suitability estimated from niche models predicts the upper limit of local abundance. American Naturalist 174: 282-291.

72. Buckley LB, Urban MC, Angilletta MJ, Crozier LG, Rissler LJ, et al. (2010) Can mechanism inform species' distribution models? Ecology Letters 13: 1041-1054.

73. Bradshaw WE, Holzapfel CM (2006) Evolutionary response to rapid climate change. Science 312: 1477-1478.

74. Buisson L, Thuiller W, Casajuss N, Lek S, Grenoillet G (2010) Uncertainty in ensemble forecasting of species distribution. Global Change Biology 16: $1148-1157$.

75. Thuiller W (2004) Patterns and uncertainties of species' range shifts under climate change. Global Change Biology 10: 2020-2027.

76. Elith J, Graham CH, Anderson RP, Dudík M, Ferrier S, et al. (2006) Novel methods improve predictions of species' distributions with occurrence data. Ecography 29: 129-151.

77. Elith J, Graham CH (2009) Do they? How do they? WHY do they differ? On finding reasons for differing performances of species distribution models. Ecography 32: 66-77.

78. Elith J, Leathwick JR (2009) Species distribution models: ecological explanation and prediction across space and time. Annual Review of Ecology, Evolution and Systematics 40: 677-697. 